\title{
Automated Ultraviolet C Light Mobile Robot for Room Sterilization and Disinfection
}

\author{
Angga Rusdinar ${ }^{1 *}$, Irwan Purnama ${ }^{1,2}$, Azam Zamhuri Fuadi ${ }^{1}$, H. Adiluhung ${ }^{3}$, \\ M. Wicaksono ${ }^{4}$, Risnanda ${ }^{4}$, Ratih Asmara Ningrum ${ }^{2}$ \\ ${ }^{1}$ School of Electrical Engineering, Telkom University, Jl. Telekomunikasi No.1, Sukapura, Bandung 40257, \\ Indonesia \\ ${ }^{2}$ National Research and Innovation Agency (BRIN), Jl. Sangkuriang, Cisitu, Bandung 40135, Indonesia \\ ${ }^{3}$ Creative Industrial Faculty, Telkom University, Jalan Telekomunikasi No.1, Sukapura, Bandung 40257, \\ Indonesia \\ ${ }^{4}$ Research and Development Dept., Narutindo Tech., Jl. Telekomunikasi No.1, Sukapura, Bandung 40257, \\ Indonesia
}

\begin{abstract}
The number of COVID-19 cases in Indonesia has increased significantly of late. Therefore, isolation rooms are needed in hospitals for patient treatment. Room sterilization and disinfection are strictly required as it is mandatory to protect the medical personnel. Chemical and physical methods can be used for sterilization and disinfection. Of these, the ultraviolet C (UVC) light method is the best because it has no residual. Even though UVC light is hazardous for humans' skin and eyes, such hazard can be avoided by eliminating human operators during usage. Thus, we developed a mobile robot with a UVC light system installed at the top and bottom to emit UVC light. We called this robot the Automated UVC Light Mobile Robot (AUMR). The AUMR can be operated automatically as it has a magnetic line sensor and employs a fuzzy inference system algorithm for its movement. The experiment showed that UVC light has good sterilization and disinfection performance in three room types: positive-pressure rooms, negative-pressure rooms, and standard public rooms.
\end{abstract}

Keywords: $\quad$ Automated; Automated UVC light mobile robot (AUMR); Disinfection; Mobile robot; Sterilization; Severe acute respiratory syndrome coronavirus 2 (SARS-CoV-2); Ultraviolet C (UVC) light

\section{Introduction}

Since the first case of coronavirus disease 2019 (COVID-19) was found in Wuhan, China, the COVID-19 cases have significantly increased on a pandemic scale. The spread of the virus causing COVID-19, severe acute respiratory syndrome coronavirus 2 (SARS-CoV2 ), has had terrible effects. It has not only resulted in massive human casualties but has also wreaked havoc on the economies of several countries (Berawi et al., 2020). In many cases, death results when the infection develops into acute pneumonia. Testing, tracking, and isolation are helping stop the spread of the virus, but even though isolation technologies for confirmed patients have been developed, such as the modular isolation unit proposed by Yatmo et al. (2021), the infection risk for healthcare workers is still high. 
Until recently, no effective treatment for COVID-19 has been found. While the antiviral strategy is still being developed, patients have been given numerous types of antibiotics for the prevention and treatment of bacterial co-infection and secondary bacterial infections. Although antibiotics do not directly affect SARS-CoV-2 multiplication, viral respiratory infections often lead to bacterial pneumonia. Co-infection and secondary bacterial infection are critical factors that determine the severity and mortality of the patients (Mirzaei et al., 2020). The overuse of antibiotics, however, may cause antibiotic-resistant bacteria, which can also endanger not only patients but also healthcare workers due to bacterial airborne transmission. Besides the use of personal protective equipment to avoid direct transmission of the virus and bacteria, room surfaces should be regularly sterilized and disinfected to inhibit indirect transmission therefrom.

Based on the No. 86/2013 regulation of the Minister of Health of the Republic of Indonesia, technologies used for medical purposes must meet several requirements, such as: (a) safety, quality, and proven benefits; (b) appropriateness and affordability; and (c) ability to protect the public from the risks of using and misusing medical devices. Thus, the sterilization and disinfection method used for preventing the transmission of SARS CoV-2 should meet all these requirements. The sterilization and disinfection method using the ultraviolet C (UVC) light technology integrated with a mobile robot meets these requirements. Compared to other sterilization and disinfection methods, however, the UVClight-technology-based mobile robot needs complex components and is thus relatively costly. Some companies have already developed this technology, such as UVD-Robot from Denmark, Finsen Technologies from the UK, and Mediland from Taiwan, but they are too costly (Ackerman, 2020; Finsen Tech, 2020; Mediland, 2020). Therefore, research is required to build the same technology at a lower cost. Such research can also encourage the development and application of similar technologies in Indonesia.

In this paper, an automated UVC-light-technology-based mobile robot for room sterilization and disinfection is introduced. The rest of the paper is organized as follows. Section 2 presents the research methods; section 3, the results; and section 4, the discussion and conclusion.

\section{Methods}

This study consisted of three parts. The first was a review of literature related to sterilization and disinfection methods. Besides discussing the studies that have been conducted on mobile robots, the focus in this part was finding the results of experiments on SARS-CoV-2 inactivation using UVC light so that the proper UVC light dose could be used. The number of UVC lamps used in the previous experimental studies could have been different, thus resulting in different light intensity numbers. Therefore, the same UVC light dose must be used in the mobile robot design even though the number of lamps is different from those in the previous studies. The second part of this study was designing the automated UVC-light-technology-based mobile robot, which consisted of two main parts: the UVC light system and the mobile robot system. The third and last part of this study involved performance verification. This part was done to verify: (a) the UVC light dose by measuring the UVC light intensity; (b) the preliminary test results; and (c) the mobile robot localization and movement control. The steps of the research method are shown in Figure 1. 


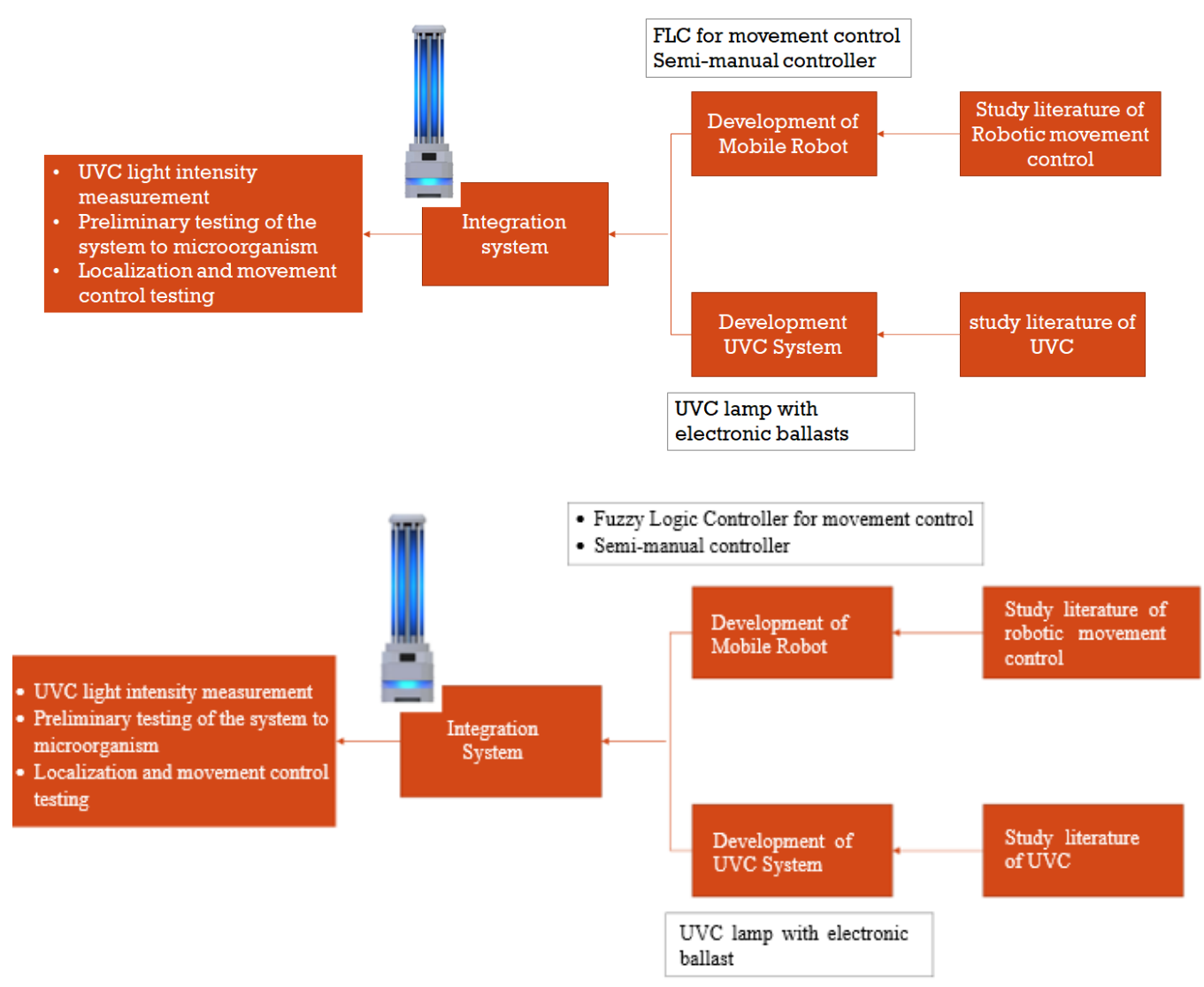

Figure 1 Diagram of the research method used in this study

\subsection{UVC Light and Its Dose Calculation}

UVC light is electromagnetic radiation with a $200-280 \mathrm{~nm}$ wavelength range. Besides UVC light, there are three other types of spectral light areas: UVV light (100-200 nm), UVB light (280-315 nm), and UVA light (315-400 nm) (Vázquez et al., 2006). UV light is emitted by the sun with three different wavelengths: UVA, UVB, and UVC, but only UVA and UVB reach the earth's surface as UVC light is usually absorbed by the ozone layer in the atmosphere.

Two types of lamps are used to artificially emit UV light: low- and medium-pressure mercury lamps. Low-pressure mercury lamps are germicidal lamps, such as the most widely used lamps (i.e., the ordinary fluorescent lamp), but the tube does not use phosphorus fluorescence. As for the medium-pressure mercury lamps, an example is the high-intensity-discharge lamp, which is often used in industry for water treatment.

When UVC light is used for disinfection purposes, the number of microorganisms after time $t$ follows the equation below (Guettari et al., 2021).

$$
d N / d t=-Z I N
$$

where $I\left(\mu \mathrm{W} / \mathrm{cm}^{2}\right)$ and $Z\left(\mathrm{~cm}^{2} / \mu \mathrm{Ws}\right)$ are the UV light intensity and the microorganism susceptibility factor, respectively. The number of inactivated microorganisms also depends on the environmental conditions, room configuration, lamp position, air condition, movement, etc. For the UVC light dose, it can be calculated using the equation below.

$$
D=I t,
$$

where $D\left(\mu \mathrm{J} / \mathrm{cm}^{2}\right)$ and $t(\mathrm{~s})$ are the UVC light dose and the irradiation time, respectively. Through Equation 2, the appropriate UVC light dose will be determined by using different amounts of UVC light. 


\subsection{Mechanism of Microorganism Inactivation}

The mechanism of UVC light's microorganism inactivation is undermining the genetic material in the virus's nucleus or nucleic acid (Chang et al., 1985). As the UVC light especially in the $250-270 \mathrm{~nm}$ wavelength range is strongly absorbed by the microorganism's nucleic acid, such wavelength range is the deadliest. UVC light with a $262 \mathrm{~nm}$ wavelength is the germicidal peak wavelength or the germicidal spectrum (Gurzadyan et al., 1995).

The emitted light damages the DNA and RNA of microorganisms through the pyrimidine molecule. In particular, thymine (found only in the DNA) produces cyclobutene dimer. When the thymine molecule dimerizes, the nucleic acid becomes very difficult to replicate, and if replication occurs, it often produces defects that prevent the microorganisms' survival (Dai et al., 2012; Perdiz et al., 2000). Some researches have shown that UVC light effectively deactivates coronaviruses, including SARS-CoV-1 (Darnell et al., 2004; Darnell and Taylor, 2006). In the study by Storm et al. (2020), UVC light was found to be a powerful tool that could be applied extensively in a wide range of room facilities. Under $0.849 \mathrm{~mW} / \mathrm{cm}^{2} \mathrm{UVC}$ irradiance, partial inactivation occurred from $0.8 \mathrm{~s}$ exposure while the SARS-CoV-2 infectivity was reduced to below detectable levels in as little time as $9 \mathrm{~s}$ for the dried virus. Wang reported the effectiveness of UV light for bacteria inactivation (Wang et al., 2019). Inactivation efficiency $\left(0.5,2.2\right.$, and 3.1 logarithmic orders) was obtained at a $370 \mathrm{~J} / \mathrm{m}^{3} \mathrm{UV}$ light exposure dose under UVA (365 nm), UVC (254 nm), and UVD (185 nm) light sources. Such dose was used to calculate the operation disinfection time of the UVC-light-technologybased mobile robot proposed in this work.

\subsection{Automated UVC Light Mobile Robot (AUMR)}

The Automated UVC Light Mobile Robot (AUMR) that was built in this work has the following characteristics: (1) it can be used for the sterilization and disinfection not only of the air (aerosol) in isolation or other medical rooms but also of the floors in rooms or hallways, using a ground UVC lamp; (2) its position control and navigation are carried out in real time either automatically or manually, using the magnetic line sensor technology or via remote control; and (3) the fuzzy inference system (FIS) algorithm is used in the AUMR navigation system. The main parts of the AUMR system are shown in Figure 2. The system has two parts: a mobile robot system and a UVC light system.

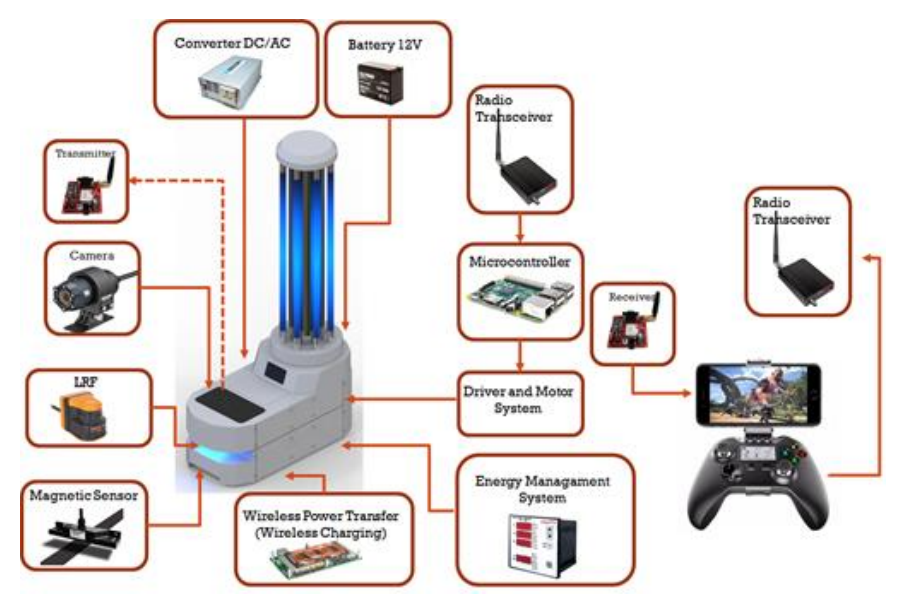

Figure 2 The Automated UVC Light Mobile Robot (AUMR) system

As shown in Figure 2, the mobile robot is moved by a differential wheel system, where each main wheel is connected to a brushed DC motor. This system is easier to control and has fewer components than the conventional system. For the movement control, a 
microcontroller is used for processing the data from the camera and the magnetic sensor and for sending a command signal to all the actuators.

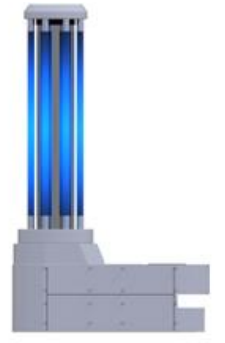

(a)

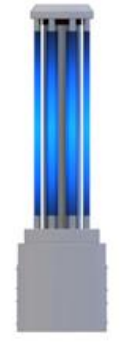

(b)

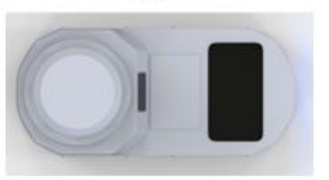

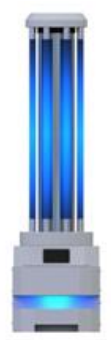

(c)

(d)

Figure 3 The Automated UVC Light Mobile Robot (AUMR) shape: (a) left/right side; (b) back; (c) front; and (d) top

For the UVC light system, all the UVC lamps are driven by an electronic ballast, and its power is drawn from a $900 \mathrm{VA}$ uninterruptable power system. A $54 \mathrm{AH}$ valve-regulated lead acid battery is used for energy storage so that the UVC light system can operate for about 3-4 h.

\subsection{Localization and Movement Control}

The most important capabilities that mobile robots should be provided are localization and navigation. Research on the localization and navigation of mobile robots has been carried out, and various tools have been used for determining the position of the mobile robot in its environment, such as laser-range-finder sensors and encoders (Rusdinar et al., 2010). Estimation using axis maps based on light detection and ranging measurements has also been introduced, which can be implemented in mobile robots (Gallant et al., 2016). However, all the presented methods are relatively costly, and low-cost methods should thus be developed. An FIS is also used to control mobile robots so they would reach their exact desired position (Rusdinar and Kim, 2013). Therefore, a semi-manual control method combined with FIS and a remote-control system monitored by a wireless camera can be the optimal methods. Monitoring is effectively done by the AUMR operator.

Besides semi-manual control via remote control, for localization and movement control, the mobile robot can follow the magnetic line or track guide installed on the floor of the hospital's hallway using magnetic tape. An MGS1600GY magnetic guide sensor is used for detecting and reporting the position of the magnetic field along its horizontal axis. The sensor detects the line or track guide on the floor to be followed by the robot. The magnetic tape will direct the AUMR, which will sterilize and disinfect each public or isolation room. To provide position information to the AUMR, some parts of the magnetic line were arranged to form several patterns indicating information on the code of movements. Figure 4 shows the pattern of the magnetic line. In the experiment in this study, four patterns were generated to provide information on the points where the AUMR must turn left, turn right, speed up, and stop to scan the barcode.

The accuracy of the AUMR's movement along the magnetic line is controlled by a fuzzy logic controller (FLC). The definition of the control position follows the rules regarding the two membership functions of input (error [ $e]$ and delta error [de]) and the membership function of output (speed [V]), as shown in Figure 5. The error $(e)$ fuzzy set consists of "left," "middle left," "center," "middle right," and "right." 


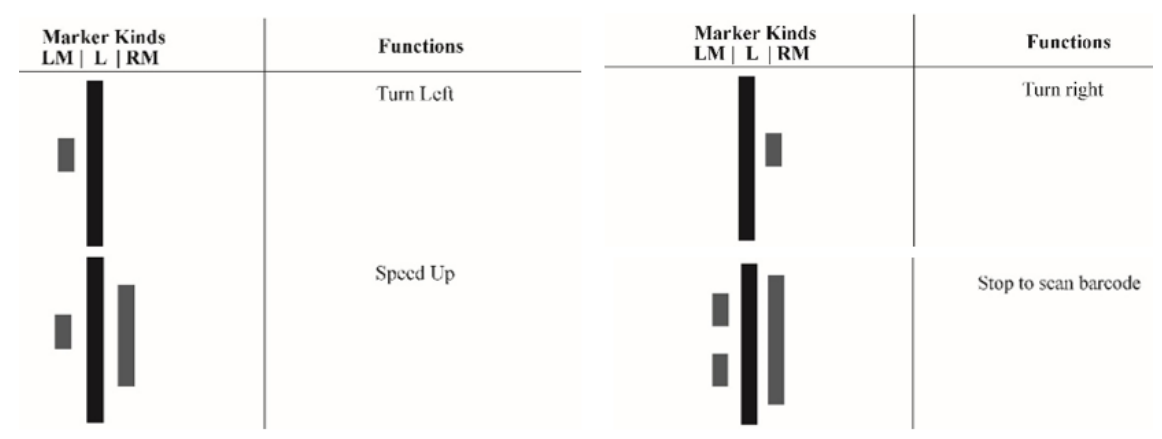

Figure 4 Magnetic line marker

These denote the positions of the AUMR on the magnetic line. The delta error $(\mathrm{de})$ fuzzy set consists of "negative delta error," "middle negative delta error," "zero delta error," "middle positive delta error," and "positive delta error." The delta error membership function denotes the changes in the error position from the prior error position (at time $t-1$ ) to the current error position. The linguistic variables of the fuzzy sets of the output membership functions are "slow," "medium," and "fast." These denote the speed of the AUMR, which is represented by the pulse width modulation output.

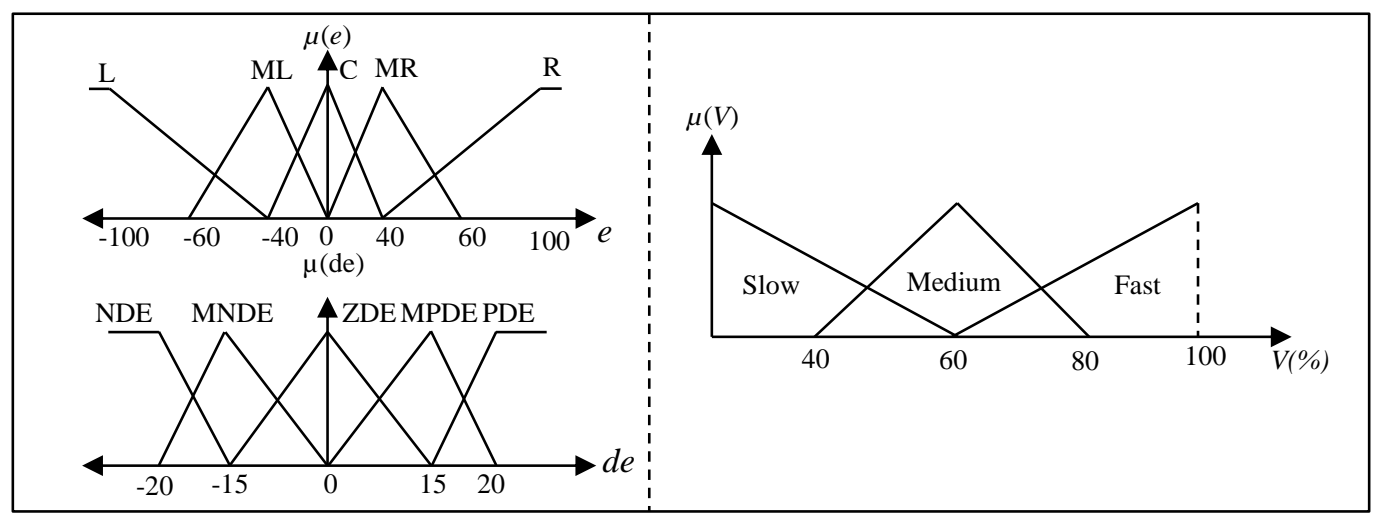

Note: $\mathrm{L}=$ left; $\mathrm{ML}=$ middle left; $\mathrm{C}=$ center; $\mathrm{MR}=$ middle right; and $\mathrm{R}=$ right; $\mathrm{NDE}=$ negative delta error; $\mathrm{MNDE}=$ middle negative delta error; $\mathrm{ZDE}=$ zero delta error; $\mathrm{MPDE}=$ middle positive delta error; and PDE = positive delta error.

Figure 5 Membership function of the fuzzy inference system

Table 1 Rule membership function

\begin{tabular}{cccccc|ccccc}
\hline \multirow{2}{*}{ Error } & \multicolumn{4}{|c|}{ Left wheel } & \multicolumn{5}{c}{ Right wheel } \\
\cline { 2 - 10 } & L & ML & C & MR & R & L & ML & C & MR & R \\
\hline & & & & & & & & & & \\
NDE & S & S & S & M & F & F & M & M & S & S \\
MNDE & S & S & S & M & F & F & M & M & S & S \\
ZDE & S & M & M & M & F & F & M & M & M & S \\
MPDE & S & M & M & S & F & F & S & S & M & S \\
PDE & S & M & M & S & F & F & S & S & M & S \\
\hline
\end{tabular}

Note: $\mathrm{NDE}$ = negative delta error; $\mathrm{MNDE}=$ middle negative delta error; $\mathrm{ZDE}=$ zero delta error; $\mathrm{MPDE}=$ middle positive delta error; $\mathrm{PDE}=$ positive delta error; $\mathrm{L}=$ left; $\mathrm{ML}=$ middle left; $\mathrm{C}=$ center; $\mathrm{MR}=$ middle right; $\mathrm{R}=$ right; $\mathrm{S}=$ slow; $\mathrm{M}=$ medium; and $\mathrm{F}$ = fast.

The intersection of the error in the AUMR current position and the delta error with membership functions $\mu(e)$ and $\mu(d e)$ is the fuzzy set $\mu(V)$, written as the equation below. 


$$
\mu(V)=\operatorname{Min}[\mu(e), \mu(d e)]
$$

To obtain the final fuzzy output in the speed of the right and left wheels, there are 50 rules for the two wheels' speed combination. The rules are listed in Table 1 . The final fuzzy output is determined using the equation below.

$$
V=\frac{\sum_{i=1}^{n}(\mu i . z i)}{\sum_{i=1}^{n} \mu i}
$$

where $\mu_{i}$ is the aggregate output membership function and $z_{i}$ is the output result for every rule.

\section{Results and Discussion}

\subsection{UVC Light Intensity}

The information regarding the UVC light intensity (irradiance) is very important because it will be used for the UVC light dose calculation. The measurement is done by laying the sensor on the ground as the first (I) position and at the middle of the lamp tower height as the second (II) position. The distance of the sensor is measured from the center of the lamp tower. The UVC light power intensity values are shown in Table 2.

Table 2 Results of the UVC lamp test

\begin{tabular}{ccc}
\hline Position & Distance & Intensity \\
\hline \multirow{2}{*}{ I } & $100 \mathrm{~cm}$ & $0.291 \mathrm{~mW} / \mathrm{cm}^{2}$ \\
& $200 \mathrm{~cm}$ & $0.144 \mathrm{~mW} / \mathrm{cm}^{2}$ \\
& $300 \mathrm{~cm}$ & $0.071 \mathrm{~mW} / \mathrm{cm}^{2}$ \\
\hline \multirow{2}{*}{ II } & $100 \mathrm{~cm}$ & $0.037 \mathrm{~mW} / \mathrm{cm}^{2}$ \\
& $200 \mathrm{~cm}$ & $0.010 \mathrm{~mW} / \mathrm{cm}^{2}$ \\
& $300 \mathrm{~cm}$ & $0.005 \mathrm{~mW} / \mathrm{cm}^{2}$ \\
\hline
\end{tabular}

Table 3 Blank spot areas

\begin{tabular}{cc}
\hline Side & Distance \\
\hline Front & $17 \mathrm{~cm}$ \\
Left/right & $19 \mathrm{~cm}$ \\
Back & $6 \mathrm{~cm}$ \\
\hline
\end{tabular}

The blank spot area is also measured so that the mobile robot can be maximally operated in a room by choosing the right position. The UVC light intensity in this area is 0 because the light radiance is blocked by the mobile robot's body. The blank spot area is measured from each side of the mobile robot, as shown in Table 3 and Figure 6.

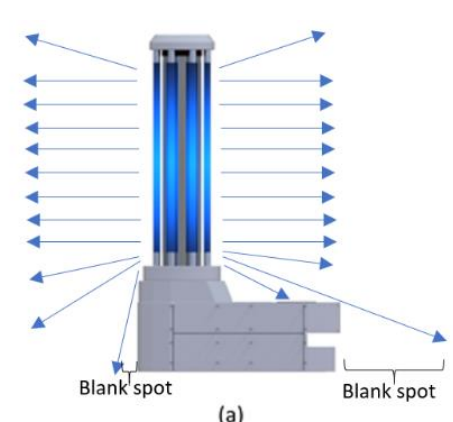

(a)

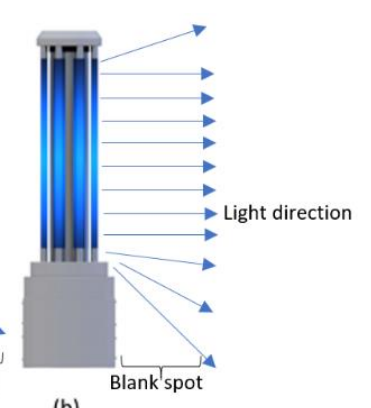

(b)

Figure 6 Illustration of the blank spot area 


\subsection{Preliminary Disinfection Test}

It is well known that COVID-19 is strongly related to bacterial co-infection. Thus, we performed a preliminary test using airborne bacterial sterility assay, where the colony number was calculated before and after the UVC light exposure through the AUMR. The test consisted of the following three steps.

- Room sterilization was carried out for 10 min with a series of UVC lamps $(36 \mathrm{~W} \times 6$ lamps). Sterility was monitored using the passive and active methods.

- In the passive method, a petri dish ( $\varnothing 90 \mathrm{~mm}$ ) containing $\pm 25 \mathrm{ml}$ nutrient agar was left open for $15 \mathrm{~min}$ before and after the room was sterilized.

- The active method was carried out using an air sampler (MAS-100VF - Merck) with a cap with a $300 \times 0.6 \mathrm{~mm}$ hole. The system used a petri dish $(\varnothing 90 \mathrm{~mm})$ containing a \pm 25 $\mathrm{ml}$ nutrient agar medium. The flow rate of the tool was $100 \mathrm{~L} / \mathrm{min}$, and the volume of the sample was $1,000 \mathrm{~L}$.

Table 4 Preliminary test results

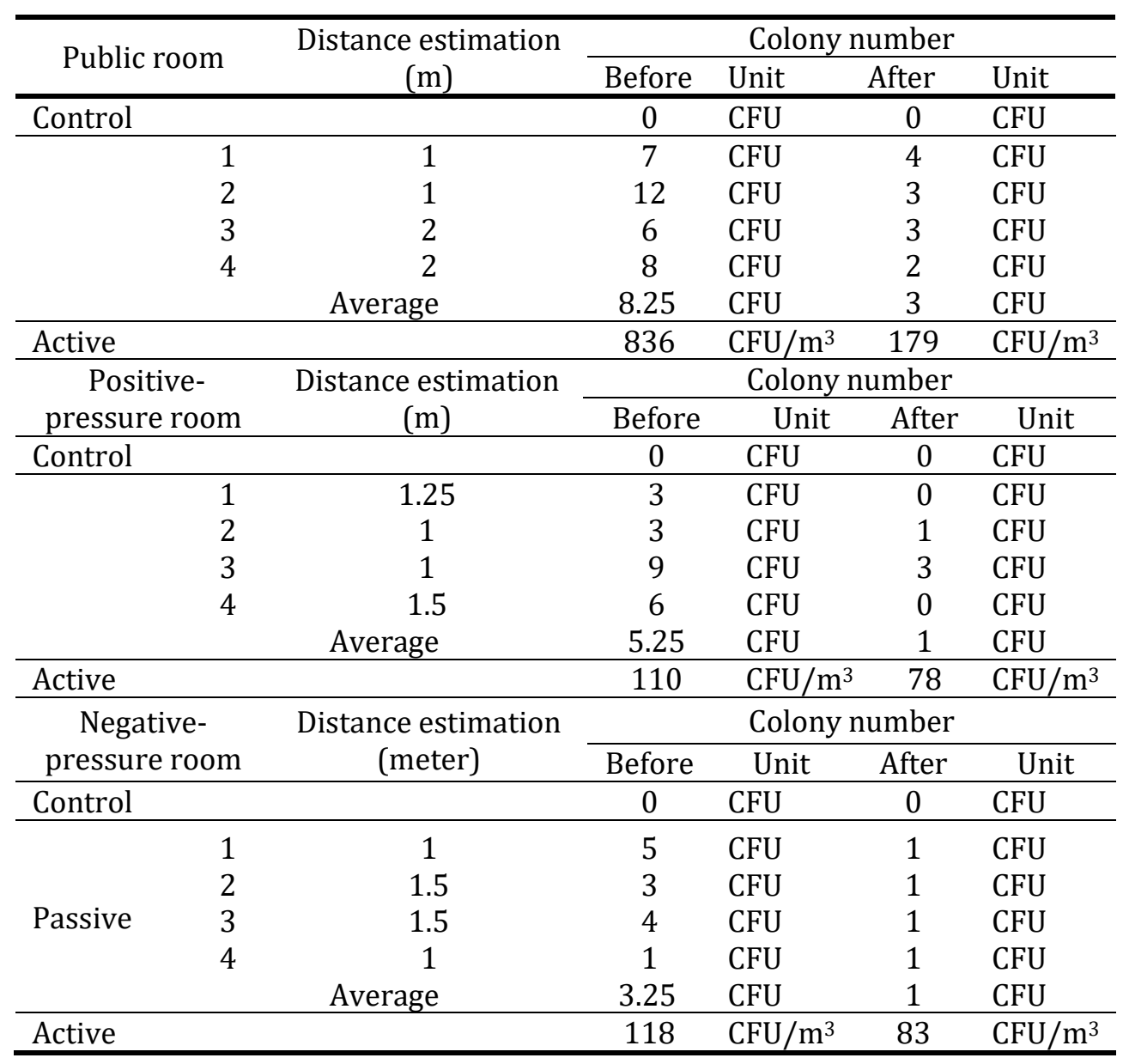

The test was carried out in three room types: a positive-pressure $(10-15 \mathrm{kPa})$ room representing the normal operating room, a negative-pressure ( -15 to $-20 \mathrm{kPa})$ room representing an isolation room, and a standard public room. The results showed that after 10-min UVC light exposure of the rooms through the AUMR, the bacteria colony number in each room was significantly reduced. Further study is needed, however, to determine the optimal UVC light exposure time for inactivating airborne bacteria and SARS CoV-2. 


\subsection{Localization and Movement Control}

Instead of the manual movement control system through the use of a camera remotecontrol device, the localization system using a magnetic line is reported herein. The localization system was developed so that the mobile robot could follow the magnetic line with less errors and knows its last position. To determine the performance of this system, the mobile robot was simulated to follow the track shown in Figure 7. This track represented the hospital's hallway. The patterns of the magnetic line were attached to the A-H points on the hallway floor, which represent the points that should be reached by the mobile robot.

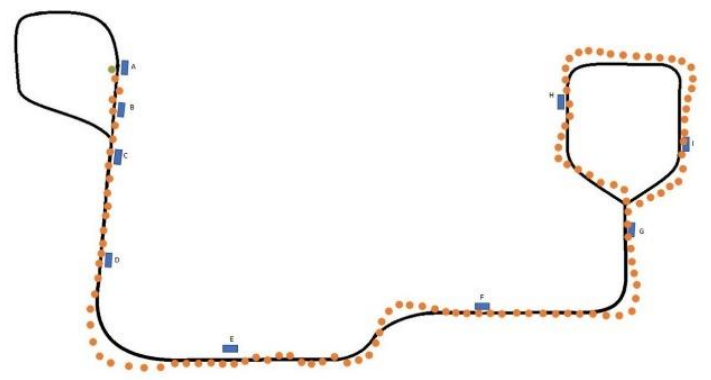

Figure 7 Experimental track map

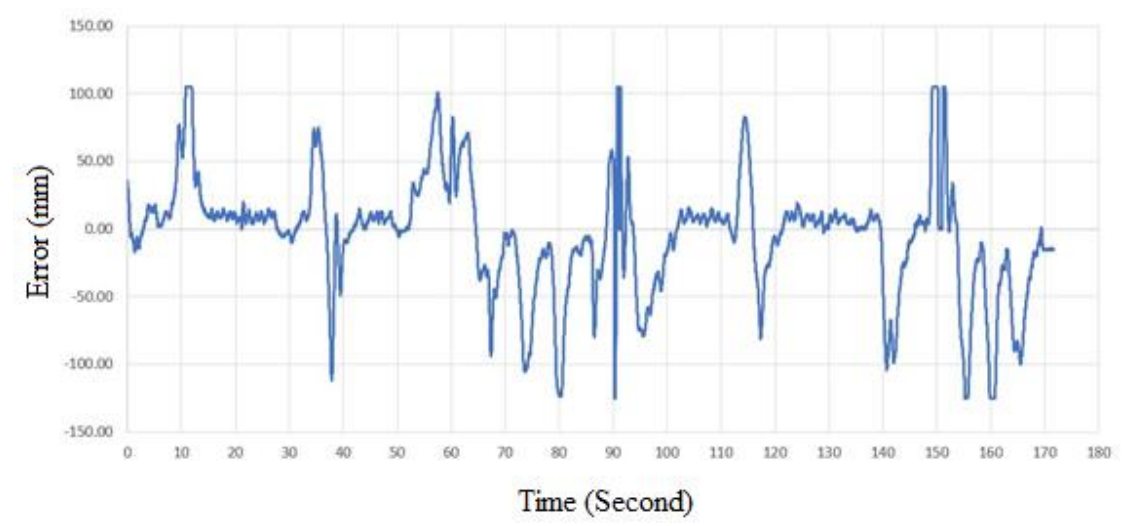

Figure 8 Movement error

Figure 7 shows that the mobile robot followed the magnetic line, but at the time of the turn part, an error occurred. This error was relatively small, however, and did not affect the AUMR's performance. Improving the FLC rule by adjusting the subset and delta errors can solve this problem. The detailed motion control error is shown in Figure 8.

\section{Conclusions}

Our study showed that the developed AUMR was able to reduce and kill airborne bacteria. It can thus be used to disinfect different types of rooms (e.g., isolation, operating, and public rooms) contaminated with hazardous bacteria that may be associated with COVID-19. On the basis of the study by Strom et al. (2020), the AUMR should be operated for $2.3 \mathrm{~s} 1 \mathrm{~m}$ away from the object for partial bacteria inactivation. As for the virus infectivity reduction to below detectable levels, the AUMR should be operated for $26.3 \mathrm{~s}$ for dried viruses and for $11.7 \mathrm{~s}$ for wet viruses. A greater distance means that more time is needed to reach the right dose for virus inactivation. 


\section{Acknowledgements}

This work was supported by the Program of COVID-19 Research Consortium and Innovation of the Indonesian Ministry of Research and Technology and by Indonesia Endowment for Education of the Indonesian Ministry of Finance. We thank the Information and Autonomous Control System Laboratory, Telkom University, the Biosafety Level-3 Laboratory, and the Technical Implementation Unit for Instrumentation Development of the Indonesian Institute of Sciences for making this work possible.

\section{References}

Berawi, M.A., Suwartha, N., Kusrini, E., Yuwono, A.H., Harwahyu, R., Setiawan, E.A., Yatmo, Y.A., Atmodiwirjo, P., Zagloel, Y.T., Suryanegara, M., Putra, N., Budiyanto, M.A., Whulanza, Y., 2020. Tackling the COVID-19 Pandemic: Managing the Cause, Spread, and Impact. International Journal of Technology, Volume 11(2), pp. 209-214

Chang, J.C., Ossoff, S.F., Lobe, D.C., Dorfman, M.H., Dumais, C.M., Johnson, J.D., 1985. UV Inactivation of Pathogenic and Indicator Microorganisms. Applied and Environmental Microbiology, Volume 49(6), pp. 1361-1365

Dai, T., Vrahas, M.S., Murray, C.K., Hamblin, M.R., 2012. Ultraviolet C Irradiation: An Alternative Antimicrobial Approach to Localized Infections. Expert Review of Antiinfective Therapy, Volume 10(2), pp. 185-195

Darnell, M.E., Subbarao, K., Feinstone, S.M., Taylor, D.R., 2004. Inactivation of the Coronavirus that Induces Severe Acute Respiratory Syndrome, SARS-CoV. Journal of Virological Methods, Volume 121(1), pp. 85-91

Darnell, M.E., Taylor, D.R., 2006. Evaluation of Inactivation Methods for Severe Acute Respiratory Syndrome Coronavirus in Noncellular Blood Products. Transfusion, Volume 46(10), pp. 1770-1777

Ackerman, E., 2020. Autonomous Robots Are Helping Kill Coronavirus in Hospitals. Available Online at https://spectrum.ieee.org/automaton/robotics/medicalrobots/autonomous-robots-are-helping-kill-coronavirus-in-hospitals, Accessed on March 30, 2020

Finsen Tech, 2020. What is UVC Disinfection, and How Can It Kill COVID-19 in Your Workplace? Available Online at https://www.finsentech.com/what-is-uvcdisinfection-and-how-can-it-kill-covid-19-in-your-workplace/, Accessed on April 2, 2020

Gallant, M.J., Marshall, J.A., 2016. Two-Dimensional Axis Mapping using LiDAR. IEEE Transactions on Robotics, Volume 32(1), pp. 150-160

Guettari, M., Gharbi, I., Hamza, S., 2021. UVC Disinfection Robot. Environmental Science and Pollution Research, Volume 28, pp. 40394-40399

Gurzadyan, G.G., Gorner, H., Schulte-Frohlinde, D., 1995. Ultraviolet (193, 216 and $254 \mathrm{~nm}$ ) Photoinactivation of Escherichia coli Strains with Different Repair Deficiencies. Radiation Research, Volume 141(3), pp. 244-251

Mediland, 2020. Hyper Light Disinfection Robot. Available Online at https://www.mediland.com.tw/mediland/pages_en/product_info.aspx?aid=155, Accessed on April 2, 2020

Mirzaei, R., Goodarzi, P., Asadi, M., Soltani, A., Aljanabi, H.A.A., Jeda, A.S., Dashtbin, S., Jalalifar, S., Mohammadzadeh, R., Teimoori, A., Tari, K., Salari, M., Ghiasvand, S., Kazemi, S., Yousefimashouf, R., Keyvani, H., Karampoor, S., 2020. Bacterial Co-Infections with SARS-CoV-2. IUBMB Life, Volume 72(10), pp. 2097-2111 
Perdiz D., Gróf, P., Mezzina, M., Nikaido, O., Moustacchi, E., Evelyne, S., 2000. Distribution and Repair of Bipyrimidine Photoproducts in Solar UV-Irradiated Mammalian Cells. Journal of Biological Chemistry, Volume 275(35), pp. 26732-26742

Rusdinar, A., Kim, J., Kim, S., 2010. Error Pose Correction of Mobile Robot for SLAM Problem Using Laser Range Finder based on Particle Filter. In: International Conference on Control, Automation and System 2010 (ICCAS-2010), Gyeonggi-do, South Korea

Rusdinar, A., Kim, S., 2013. Vision-Based Indoor Localization using Artificial Landmarks and Natural Features on the Ceiling with Optical Flow and a Kalman Filter. International Journal of Fuzzy Logic and Intelligent Systems, Volume 13(2), pp. 133-139

Storm, N., McKay, L.G.A., Downs, S.N., Johnson, R.I., Birru, D., Samber, M., Willaert, W., Cennini, G., Griffiths, A. 2020. Rapid and Complete Inactivation of SARS-CoV-2 by Ultraviolet-C Irradiation. Scientific Reports, Volume 10, 22421, https://doi.org/10.1038/s41598-020-79600-8

Vázquez, M., Hanslmeier, A., Arnold, 2006. Ultraviolet Radiation in the Solar System. Springer: Dordrecht, The Netherlands

Wang, C., Lu, S., Zhang, Z., 2019. Inactivation of Airborne Bacteria using Different UV Sources: Performance Modeling, Energy Utilization, and Endotoxin Degradation. Science of the Total Environment, Volume 655, pp. 787-795

Yatmo, Y.A., Harahap, M.M.Y., Atmodiwirjo, P., 2021. Modular Isolation Units for Patients with Mild-to-Moderate Conditions in Response to Hospital Surges Resulting from the COVID-19 Pandemic. International Journal of Technology, Volume 12(1), pp. 43-53 